CUADERNOS DE ESTUDIOS GALLEGOS, LIX Núm. 125 (enero-diciembre 2012), págs. 13-38

ISSN: 0210-847 X DOI: $10.3989 /$ ceg.2012.125.01

\title{
A PROPORCIÓN NA ESCULTURA GALAICA DA IDADE DO FERRO
}

\author{
Manuel Santos Estévez \\ Instituto de Historia - Centro de Ciencias Humanas y Sociales \\ CSIC
}




\title{
A PROPORCIÓN NA ESCULTURA GALAICA DA IDADE DO FERRO
}

\begin{abstract}
RESUMO
O artigo analiza o uso da coñecida como Proporción Harmónica ou Proporción Áurea nun tipo concreto de esculturas no noroeste da Iberia da Idade do Ferro procedentes do sur de Gallaecia. Proponse que a aplicación dun concepto tan elaborado na solución dunha serie de problemas técnicos implica a existencia de artesáns especializados. Considérase que as esculturas de guerreiros foron un instrumento de lexitimación dun grupo social dominante nun contexto dunha sociedade de xefatura complexa. Estas esculturas, como artefactos ideolóxicos, foron usadas na Gallaecia da tardía Idade do Ferro como unha representación material do poder social.
\end{abstract}

Palabras Clave: Escultura, Gallaecia, Proporción Armónica, Xefaturas Complexas.

\section{LA PROPORCIÓN EN LA ESCULTURA GALAICA DE LA EDAD DEL HIERRO}

\section{RESUMEN}

El artículo analiza el uso de la conocida como Proporción Armónica o Proporción Áurea en un tipo concreto de esculturas en el noroeste de la Iberia de la Edad del Hierro procedentes del sur de Gallaecia. Se propone que la aplicación de un concepto tan elaborado en la solución de una serie de problemas técnicos implica la existencia de artesanos especializados.

Se considera que las esculturas de guerreros fueron un instrumento de legitimación de un grupo social dominante en un contexto de una sociedad de jefatura compleja. Estas esculturas, como artefactos ideológicos, fueron usadas en la Gallaecia de la tardía Edad del Hierro como una representación material del poder social.

Palabras Clave: Escultura, Gallaecia, Proporción Armónica, Jefaturas Complejas.

\section{PROPORTION IN THE GALLAECIAM SCULPTURE IN IRON AGE}

\section{AbSTRACT}

This paper argues for the use of the so called Harmonic Proportion or Golden Proportion in a specific kind of Iberian Iron Age sculptures from southern Gallaecia. We suggest that the employment of such a sophisticated concept in the solution of a set of technical problems points at the existence of a specialized craftsman.

We suggest that warrior sculptures were an instrument legitimating a ruling social group in the context of a complex chiefdom. These sculptures were used as ideological artefacts during Gallaecia's Late Iron Age, and as a material representation of the social power.

KEY WORDS: Sculpture, Gallaecia, Harmonic Proportion, Complex Chiefdoms. 
Recibido/Received: 12/06/2012

Aceptado/Accepted: 14/08/2012

\section{INTRODUCIÓN ${ }^{1}$}

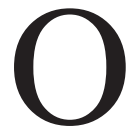

s coñecementos técnicos dos que unha determinada comunidade poda facer uso, soen estar relacionados coa complexidade social da mesma. Por esta razón, é posible propor que o coñecemento exhaustivo de certos aspectos formais da natureza poden estar relacionados coa existencia dun grupo de individuos dedicados, con maior ou menor grado de especialización, ó seu estudo e/ou aprendizaxe.

Neste artigo analízase a posibilidade do emprego da chamada Proporción Harmónica na escultura dos galaicos da Idade do Ferro. Esta escultura semella ser producida, polo menos en parte, na fase final do desenvolvemento desta cultura, momento que semella situarse entre os tempos inmediatamente anteriores á conquista romana e os inmediatamente posteriores.

Preséntase a posibilidade de que a Proporción Harmónica nas esculturas dos denominados guerreiros galaicos puido ser intencional, posto que se evidencia nun elevado número de coincidencias entre o deseño das esculturas e as liñas que trazan o coñecido como Rectángulo Áureo. Por outra banda, tamén se constata que, aínda que fose sistemática, isto no implica que fose aplicada en todos os casos.

Así mesmo, abordaranse as consecuencias sociais e culturais que implica a presenza dun concepto tan elaborado, dende o punto de vista técnico e ideolóxico, como a Proporción Harmónica. O aspecto técnico afecta á solución dunha serie de problemas que conleva a aplicación dunha proporción determinada a un produto material e o conseguinte grado de especialización do artesán, por outra banda, o ideolóxico, afecta ó uso da escultura como representación do poder no seno dunha sociedade xerarquizada e complexa.

\footnotetext{
${ }^{1}$ Quixera agradecer a axuda prestada por Pedro Díaz del Río, Marco García, César Velandia e Juan Vicent como revisores de parte ou da totalidade do texto deste artigo.
} 


\section{O Rectángulo Dourado}

A base da Proporción Harmónica está na chamada Sección Áurea ou tamén chamada Razón Extrema e Media. A Sección Áurea defínese como a relación entre dous segmentos, de tal xeito que, o segmento menor é ó maior como este é á suma dos outros dous. Para trazar unha liña de acordo coa Sección Áurea trázase unha liña XY, en cuxo extremo se debuxa a perpendicular YZ (Fig. 1). Logo divídese $\mathrm{XY}$ en dúas partes iguais, e con esta medida trázase un arco con centro en $Y$ para obter o punto $Z$, que é o extremo da perpendicular. Únense os puntos $\mathrm{XZ}$. Trazando un arco con centro en $\mathrm{Z}$, e cun radio equivalente a $\mathrm{ZY}$, córtase a hipotenusa no punto E. Logo, trazando un arco con centro en $X$ e coa medida $\mathrm{XE}$, trázase un arco que corte XY no punto N. Deste xeito, a liña XY (c) queda dividida en dous segmentos desiguais XN (a) e NY (b), obtendo deste modo a Sección Áurea, é dicir, que a relación entre $a$ e $b$ é a mesma que entre $a$ e $c$.

Pero para a análise das esculturas da Idade do Ferro imos traballar co xa mencionado Rectángulo Dourado, Áureo ou Harmónico, forma xeométrica baseada nas mesmas proporcións que a Sección Áurea, pero nunha superficie bidimensional (Fig. 1). Non é preciso o uso de números para debuxar un rectángulo que siga a Proporción Harmónica, os únicos instrumentos precisos son o escuadro e o compás. Para trazalo debuxamos un cadrado e con centro no punto $\mathrm{m}$, punto medio entre $\mathrm{AB}$, trázase un arco que corte a prolongación da base do cadrado $A B$ no punto $C$, no cal levántase unha perpendicular ata a altura do cadrado, deste xeito trázase un rectángulo, con base en $\mathrm{BC}$, que sumado ó cadrado con base en $\mathrm{AB}$ dá lugar a outro rectángulo cuxa proporción é a mesma que o rectángulo menor, esta proporción, exprésase a través da división entre a lonxitude e a anchura dos rectángulos, que en ambos casos dá 1,618. Arriba: a sección áurea. Abaixo: o rectángulo dourado. 


\section{A Proporción Harmónica ou Divina Proporción}

A Proporción Harmónica é o resultado da relación entre dúas formas xeométricas elementais derivadas, por exemplo, da partición dun segmento de liña en dúas partes desiguais, ou entre dúas superficies distintas como o rectángulo e o cadrado, de modo que a parte menor é á maior, como esta é á suma das dúas. A relación entre os termos $a: b: c$ (Fig. 1), onde $a$ e $b$ son as dúas partes e $c$ é a suma das dúas, exprésase co xa mencionado número 1,618, que en 1924 é denominado $\Phi$ por o matemático Cook ${ }^{2}$. Este número tiña sido xa bautizado como o "Número de Ouro" por Leonardo Da Vinci ou "Sección Áurea" polo astrónomo Kepler. Deste xeito, o rectángulo cuxas proporcións son o resultado da suma dun cadrado e un rectángulo cuxa proporción entre ambos é $\Phi$ é o anteriormente descrito "Rectángulo Dourado" ou "Rectángulo Áureo" e este será basicamente o instrumento de medida que imos a utilizar no noso estudo. É preciso aclarar que é pouco probable que os galaicos da Idade do Ferro tiveran formulado a proporción áurea servíndose do número 1,618 , xa que se trata dunha sociedade ágrafa, e para o desenvolvemento de operacións matemáticas de certa complexidade é necesaria a escritura ${ }^{3}$, aínda que si poderían usar proporcións ou relacións xeométricas expresadas a través do debuxo xeométrico tal e como temos visto á hora de trazar o rectángulo áureo. Esta cuestión é importante, xa que, se temos esta circunstancia en conta, cabe agardar que as proporcións das esculturas estean sempre en relación cunha figura xeométrica. Precisamente, a posibilidade de que a aplicación da Proporción Harmónica fose intencional susténtase no feito de que as coincidencias non só atinxen ás proporcións das esculturas, senón que tamén son atopadas coincidencias nas liñas que trazan unha figura concreta: o Rectángulo Áureo.

Aínda que o obxecto deste artigo non é a orixe da Proporción Áurea, pode ser interesante sinalar algunhas breves notas históricas sobre a mesma. A primeira formulación coñecida da Proporción Harmónica vén da man de Frai Luca Paccioli di Borgo que publica De Divina Proportione en 1509, na devandita obra, na segunda sección, Paccioli aplica a Sección Áurea á arquitectura e ó corpo humano. O mesmo Paccioli afirma que a Divina Proporción xa era coñecida por Platón, Pitágoras e Euclides. Por outra banda, esta mesma proporción, é atopada en construcións como o Partenón e nalgunhas aínda máis antigas en Exipto e Mesopotamia ${ }^{4}$. Polo tanto, aínda que a primeira formulación coñecida date de primeiros do século XVI, o seu coñecemento e uso podería ser moi anterior.

\footnotetext{
2 Tal e como afirma Roberto SAmpoelesi, La Divina Proporción y la Retina, Buenos Aires, Olmo Ediciones, 2006.

3 Jack Goody, La Domesticación del Pensamiento Salvaje, Madrid, Ed. Akal, 1985, páx. 22.

${ }^{4}$ Matila Gнyка, Estética de las Proporciones en la Naturaleza y en las Artes, Buenos Aires, Ed. Poseidón, 1953 e El número de oro, Buenos Aires, Ed. Poseidón, 1968.
} 
A Proporción Harmónica semella estar presente en producións materiais de diversas culturas, aínda que quixera destacar os traballos levados a cabo na América precolombina nas esculturas olmecas ${ }^{5}$, ou nas esculturas de San Agustín ${ }^{6}$. A distribución xeográfica e temporal explícase porque esta relación é observable na natureza, no ritmo de crecemento dos seres vivos, como a corna do Nautilius, na composición dos cristais, etc ${ }^{7}$. Polo tanto, dentro das culturas do Vello Mundo, en Asia Oriental e na América, a presenza podería ser resultado da observación da natureza e da transmisión e mantemento de tradicións precedentes, aínda que, en todo caso, tanto a súa observación directa na natureza como o súa aprendizaxe e aplicación á produción material implica un complexo desenvolvemento cultural e social. É posible pensar que, xa que a Proporción Harmónica está presente na natureza, é probable que a súa presenza nalgunhas construcións tivera lugar de forma intuitiva ou inconsciente por parte do escultor, pero no caso da escultura galaica veremos como a súa aplicación segue un sistema baseado nunha figura concreta: o rectángulo áureo, cuxos elementos constitutivos se relacionan con partes das esculturas de forma reiterada, mentres que noutras non é imposible atopar ditas coincidencias, é dicir, mentres nunhas se aplica a proporción de forma sistemática noutras semella ignorarse. Por outra banda, existen casos de aplicación da Proporción Áurea na escultura galaica que desbotan a posibilidade de seren explicados polo azar, como é o caso dalgúns trisqueis, deseños resultantes da confluencia de tres espirais áureas ${ }^{8}$ cuxa posición relativa difire en 120 grados tal e como se describe na Figura 2.

\section{Metodoloxía}

O mundo da escultura da Idade do Ferro do noroeste de Iberia é tremendamente amplo e o número de pezas non cesa de incrementarse; por elo debemos limitar a mostra a analizar co fin de adaptala á extensión dun artigo. Non se trata de comprobar o grado de emprego da Proporción Harmónica entre os galaicos, senón sinxelamente constatar o seu uso. Coa idea que no futuro de amplíen os casos analizar, elixíronse as figuras de guerreiros galaicos e foron desbotadas outras, aínda que, parte destas puideran ter sido deseñadas seguindo a Proporción Harmónica, e que a estrutura xeométrica empregada puidera ter sido outra

\footnotetext{
5 Beatriz. de la Fuente, Los hombres de piedra. Escultura olmeca, México, Instituto de Investigaciones Estéticas, UNAM, 1977.

${ }^{6}$ César Augusto Velandia JAgua, Iconografía funeraria en la cultura arqueológica de San Agustín-Colombia, Ibagué, Universidad del Tolima, 2011.

7 Matila Gнyка, Estética de las Proporciones..., Matila GHyкA, El número de....

8 A espiral áurea é aquela cuxa razón de crecimiento é $\Phi$. Pódese trazar dentro dun rectángulo áureo.
} 
distinta do rectángulo áureo. Tamén foron descartadas para a súa análise aquelas pezas antropomorfas desproporcionadas, de aparencia descoidada. En referencia a isto, Silva fai notar a diferenza no grado de elaboración entre as estatuas de guerreiros e a maior parte das restantes esculturas ${ }^{9}$. Finalmente, dentro do grupo de esculturas de guerreiros, soamente foron analizadas aquelas pezas que presentasen certo grado de conservación e que non se atopasen excesivamente fragmentadas. Para elo seguimos a catalogación de Calo Lourido ${ }^{10}$ e eliminamos da mostra aquelas esculturas que presentan dúbidas acerca da súa pertenza a un guerreiro. Así, podemos contabilizar un total de polo menos 26 esculturas de guerreiros galaicos entre estatuas desaparecidas, cabezas, pés, torsos e figuras case completas. Este estudo limitarase á análise daquelas pezas mellor conservadas, por elo as esculturas analizadas, todas elas no norte de Portugal, son as seguintes: 2 esculturas de Lezenho, 2 de Campos, Meixedo, Sto. Ovidio de Fafe, Sanfíns, São Julião, Sta. Comba e Vizela. Descartouse a figura do guerreiro de Refojos, en parte por ter sufrido notables transformacións e a que carecemos dun debuxo ou fotografía perfectamente frontal da peza debido á súa colocación nun pedestal. Tampouco se incluíron as estatuas de Capeludos, Sabanle, Cendufe, Mozinho e o da Cidá de Armeá por atoparse excesivamente fragmentadas. Polo tanto analizaranse un total de 10 pezas escultóricas.

Para proceder ás medicións das esculturas, aplicamos en tódolos casos o mesmo procedemento. Aplicouse o rectángulo dourado, o cal foi superposto á figura analizada en cada caso. En primeiro lugar, ó tratarse de figuras simétricas tanto de fronte como na parte posterior, procedeuse a dispor os rectángulos en posición simétrica en dobre columna, esta colocación dos rectángulos é a que posibilita a disposición simétrica dos elementos compositivos da obra. As dimensións do rectángulo empregado defínense mediante a equiparación da súa anchura á anchura da metade simétrica da peza, é dicir, que dous rectángulos dourados xustapostos suman a anchura máxima da escultura do guerreiro, que soe situarse á altura dos ombreiros. Esta forma de definir as dimensións dos rectángulos veu imposta pola circunstancia de que ningunha peza se atopase completa, polo tanto descoñecemos a altura exacta das esculturas, aínda que si coñecemos a anchura de practicamente todas. En todo caso, se estas pezas seguen a Proporción Harmónica debe existir unha proporción concreta entre anchura e altura e, se esta é a Proporción Áurea, a súa figura ten que poder inscribirse nun rectángulo dourado ou no conxunto de rectángulos dourados que consideremos, sempre e cando manteñan a proporción correcta. En todo caso, debemos sinalar

\footnotetext{
${ }^{9}$ Armando Coelho Ferreira da SiLva, A Cultura Castreja do Noroeste de Portugal, Paços de Ferreira, Museu Arqueólogico da Citânia de Sanfins, tese doutoral inédita, 1986.

10 Francisco CAlo Lourido, “Catálogo”, Madrider Mitteilungen, 44 (2003), páxs. 6-32.
} 
certa problemática con respecto á colocación dos rectángulos, xa que na maior parte dos casos non se conserva nin a cabeza nin os pés das estatuas, para corrixir este problema na medida do posible, empezouse pola medición das esculturas que conservan a cabeza, para logo, nas seguintes pezas, comprobar se colocando os rectángulos na mesma posición relativa se repetían as mesmas coincidencias. A presente proposta pretende abrir un campo de estudo na escultura da Idade do
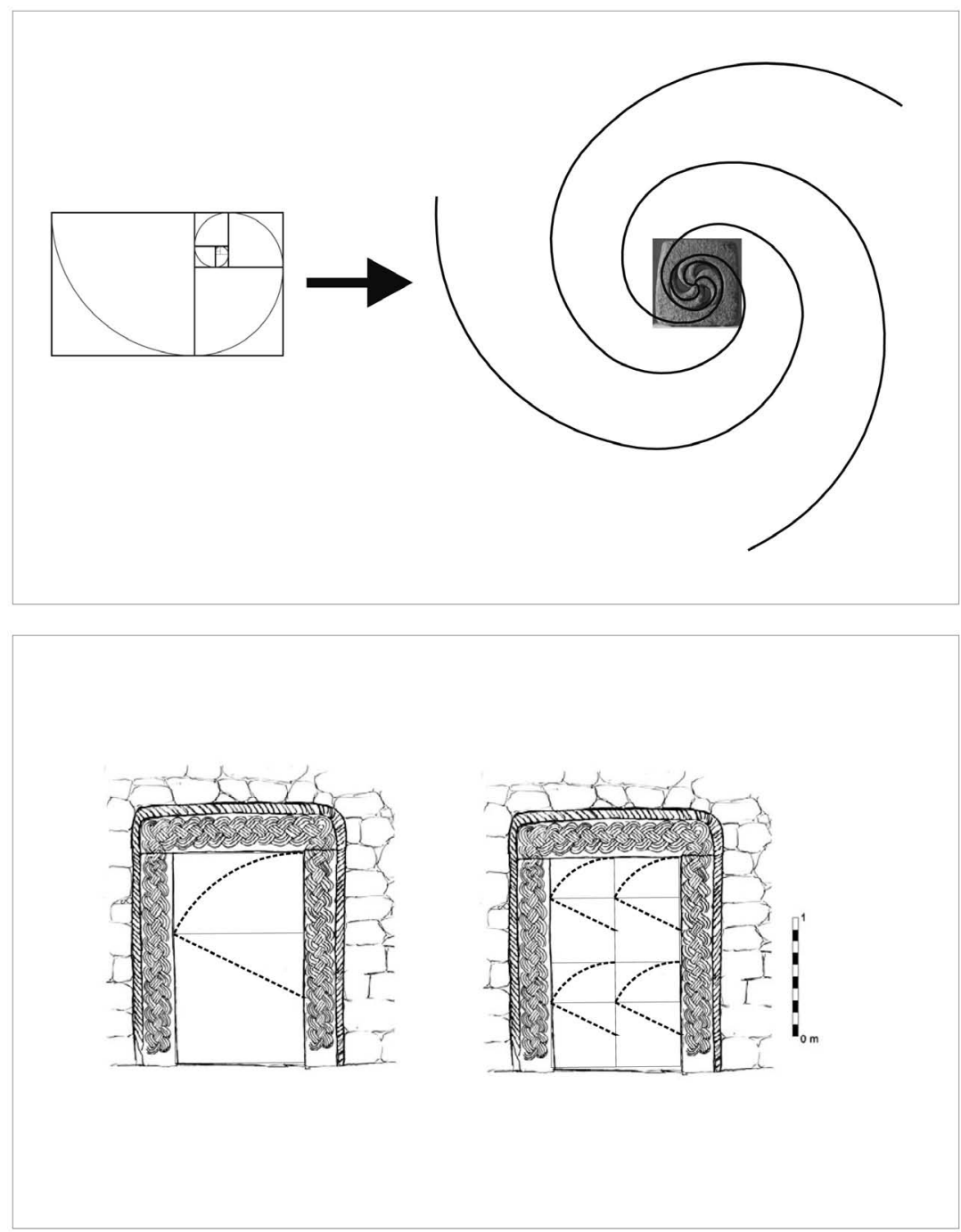

Fig. 2

Arriba: Espiral Áurea e aplicación da mesma para o deseño de trisqueis. Abaixo: porta da Cidade de Áncora. (A partir de debuxo de González Ruibal 2007a) 
Ferro, e a demostración da presenza da Proporción Áurea non se constata en tódolos casos, aínda que si a existencia dunha intencionalidade no cálculo das proporcións das estatuas.

A pesar das dificultades e limitacións mencionadas, puidéronse constatar coincidencias notables entre puntos clave dos deseños e as liñas divisorias dos rectángulos, así mesmo, como veremos na parte analítica deste traballo, tamén as diagonais e arcos trazados no interior dos rectángulos definen a disposición de diversos elementos decorativos. En calquera caso, os rectángulos dourados poderían terse colocado de moitos outros xeitos e as coincidencias seguirían sendo numerosas, isto é debido ó carácter, en certo modo, fractal da Proporción Harmónica. Un bo exemplo delo é a porta da Cidade de Áncora (Caminha) na figura 2, podemos ver como son posibles varios os sistemas que podemos seguir para comprobar a presenza do Rectángulo Dourado

$\mathrm{Na}$ antedita porta vemos que, en primeiro lugar, o vano da mesma é un perfecto Rectángulo Áureo. Do mesmo xeito, se dividimos o vano en catro partes iguais, as catro tamén serían 4 rectángulos áureos perfectos. Como prudencia metodolóxica, debemos ter presente a posibilidade de que, nalgúns casos, puidéramos atopar produtos materiais cuxas proporcións totais ou parciais puideran coincidir de forma casual coa Proporción Áurea. Por isto deberemos ter en conta que as coincidencias nas medicións son reiteradas, é dicir, que os mesmos elementos coinciden coas mesmas partes do rectángulo nun número suficiente de casos. Con isto preténdese evitar formas de aplicación da Proporción Áurea criticadas por Markowsky en referencia a medicións levadas a cabo na pirámide de Keops ou no Parthenon de Atenas ${ }^{11}$.

\section{A Proporción HARMónicA NAS ESCUlturas DE GUERREIROS}

O principal problema ó que nos enfrontamos é o estado incompleto e/ou fragmentado de tódalas esculturas. De feito, non é posible abordar a análise das proporcións en parte das pezas, aínda que tamén é certo que algunhas delas, grazas ó alto grado de fidelidade das súas proporcións, é posible aplicar o Rectángulo Dourado para a súa medición.

En resumidas contas, veremos como 6 das 10 esculturas analizadas, seguen a Proporción Harmónica e as 4 restantes ofrecen dubidas sobre da súa aplicación. Debemos sinalar que, aínda que non se presenta aquí, tamén se realizou a análise dunha figura S. João de Ver, con resultado absolutamente negativo, pero tamén é certo que a antedita obra é situada por algúns autores no Bronce Final ou inicios da ${ }^{11}$ George MarkowsKy, "Misconceptions about the golden ratio", The College Mathematics Jour-
nal, vol. 23, núm. 1 (Jan.1992), páxs. 2-19. 
Idade do Ferro ${ }^{12}$, en todo caso sería anterior ó desenvolvemento da escultura dos guerreiros galaicos que se iniciaría entre os s. II a. C. e I a. C. ${ }^{13}$ aínda que segundo outros autores serían máis serodios, é dicir, en torno ó cambio de era e vinculado ó proceso romanizador ${ }^{14}$. Así pois procedemos a expor a análise das esculturas.

\section{Lezenho 1 e 2}

Foron atopadas no adro da igrexa parroquial de Covas de Barroso (BoticasVila Real), na actualidade localízanse no Museu Arqueológico Nacional en Lisboa (Fig. 3).

Trátase de dúas esculturas que gardan entre si estreitas semellanzas, ata o punto de que é moi posible que o seu autor fose o mesmo. Unha vez aplicada a metodoloxía exposta, vemos que, respecto ás proporcións totais, semellan seguir
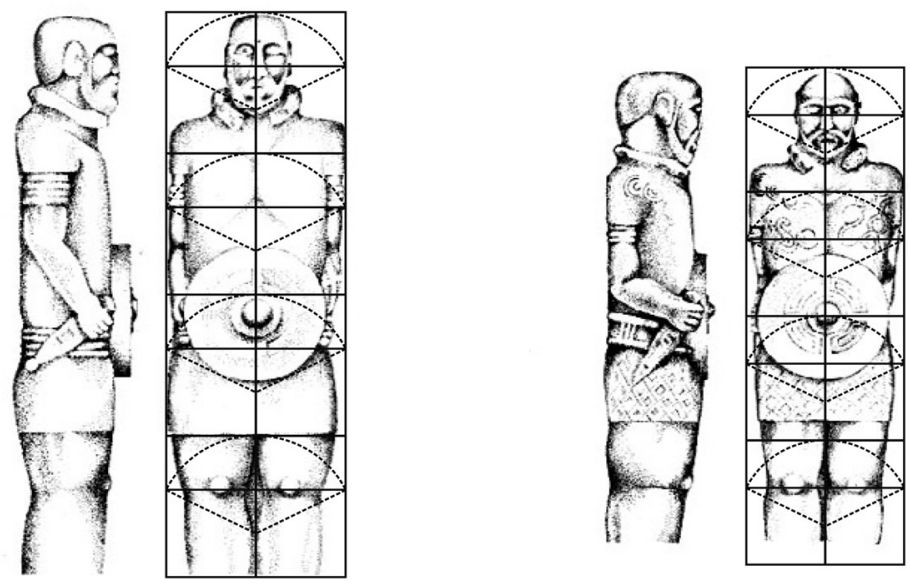

Fig. 3

Esquerda: Lezenho 1. Dereita: Lezenho 2. (A partir de debuxo de Silva, A.C.F. da. 1986)

\footnotetext{
12 Véxase na páx. 309 de Vitor Oliveira Jorge e Susana Oliveira Jorge, "Statues-Menhirs et Stèles du Nord du Portugal", Revista da Facultade de Letras: História, serie II, vol 7 (1990), páxs. 299-324.

13 Véxase nas páxs. 114, 327 e 351 de Alain Tranoy, La Galice romaine. Recherches sur le nordouest de la péninsule Ibérique dans l'Antiquité, 1981. Ver tamén na páx. 120 de Alfredo GonzÁLEZ Ruibal, "Artistic expression and material culture in Celtic Gallaecia", E-Keltoi, 6 (2004), páxs. $113-66$.

${ }^{14}$ Francisco CALO LouRIDo, "Arte, decoración, simbolismo e outros elementos de cultura material castrexa. Ensaio de síntese", en Gerardo Pereira Menaut (coord.), Estudos de Cultura Castrexa e de Historia Antiga de Galicia, Santiago de Compostela, Universidade, 1983, páxs. 178-184. Francisco Calo Lourido, A Plástica da Cultura Castrexa Galego-Portuguesa, A Coruña, Fundación Pedro Barrié de la Maza, 1994, páxs. 683, 798 e 823. Ver tamén Armando Coelho Ferreira da Silva, A Cultura Castreja do Noroeste..., páx. 292.
} 
a Proporción Áurea, xa que o deseño da figura podería estar definida por 10 rectángulos.

En ámbolos dous casos vemos como a cabeza aparece perfectamente enmarcada polos arcos e diagonais dos rectángulos superiores. As liñas horizontais coinciden coa liña inferior das viriae, liña inferior do cinto e xeonllos. No caso

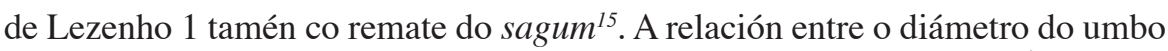
do escudo e o diámetro total do mesmo segue tamén a Proporción Áurea nos dous casos.

\section{Campos 1 e 2}

Trátase de dúas esculturas moi posiblemente vinculadas, ó igual que as dúas anteriores, ó castro de Lezenho. Na actualidade atópanse depositadas no Museu Nacional de Lisboa (Fig. 4).

Tamén semellan ter unhas proporcións totais equivalentes a 10 rectángulos. En Campos 1 as liñas horizontais coinciden coa liña inferior das viriae, a liña superior do cinto e o remate do sagum. A diferenza entre o diámetro do umbo e o escudo completo é unha relación áurea.

En Campos 2 as liñas horizontais coinciden co pico do escote, a liña inferior das viriae e os arcos da terceira parella de rectángulos definen a forma do escudo. Este é un dos dous casos nos que non existe proporción áurea entre o tamaño do umbo e do escudo.

\section{Meixedo}

Procedente de São Paio de Meixedo (Viana do Castelo), localízase no Museu Municipal de Viana do Castelo (Fig. 5). Esta figura sufriu certas transformacións e engadidos que afectaron fundamentalmente á cabeza e á decoración do escudo, polo cal non serán tidas en conta estas partes da peza para realizar as medicións.

As dimensións da escultura completa poderían coincidir con 10 rectángulos áureos. As liñas horizontais coinciden co pico do escote, as mangas do sagum, a liña superior do cinto e centro do escudo e o límite inferior do sagum. Non é posible medir as proporcións do escudo por atoparse moi alterado con respecto ó orixinal.

\footnotetext{
15 Neste caso non foi posible inclui-la parte posterior da escultura debido á súa posición actual moi próxima a una parede do museo e a que non exista un debuxo da mesma.
} 

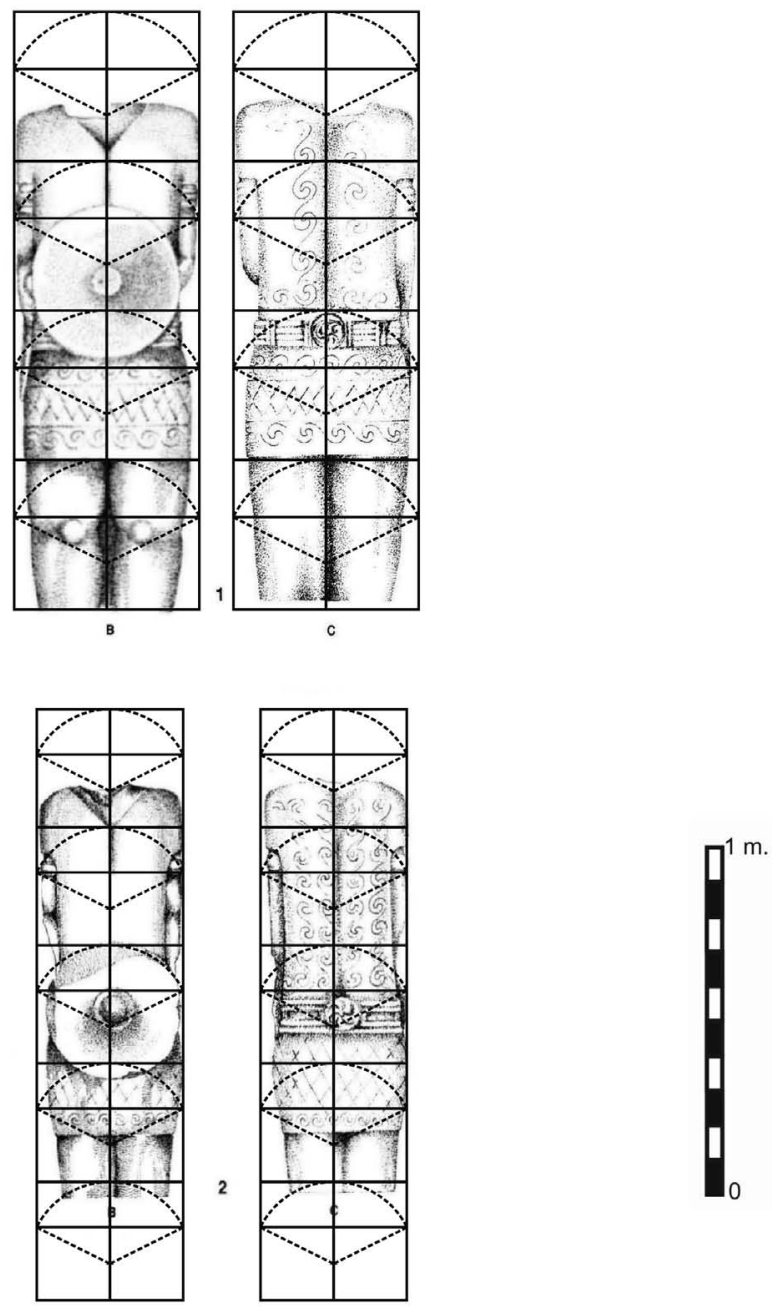

Fig. 4

Arriba: Campos 1. Abaixo Campos 2. (A partir de debuxo de Silva, A.C.F., 1986)

\section{São Julião}

Orixinario do castro de São Julião (Vila Verde-Braga), actualmente atópase no Museu Municipal de Vila Verde (Fig. 5).

Unha vez máis as proporcións xerais semellan corresponderse con 10 rectángulos áureos. Unha das liñas horizontais coincide co centro do rombo debuxado no peito, e as 3 restantes cas viriae, centro do escudo e liña superior do cinto e liña inferior do sagum. Hai Proporción Harmónica entre o diámetro do umbo e o do escudo. 

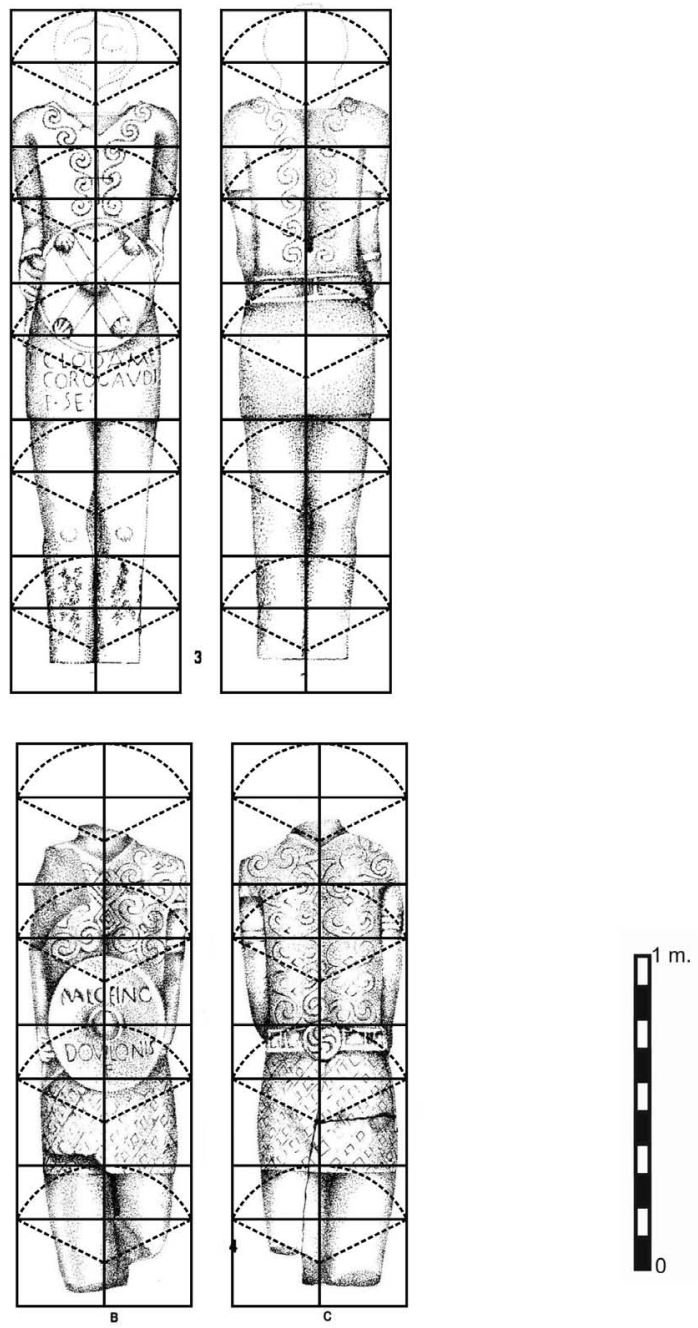

Fig. 5

Arriba: Meixedo. Abaixo: São Julião. (A partir de debuxo de Silva, A.C.F., 1986)

\section{Santo Ovidio de Fafe}

Sería orixinario do castro de Sto. Ovidio (Fafe-Guimarães). Na actualidade atópase exposto no Museu Arqueológico da Sociedade Martins Sarmento en Guimarães (Fig. 6).

A proporción da estatua completa podería ser a mesma que as restantes esculturas: 10 rectángulos, aínda que as coincidencias das liñas horizontais semellan insuficien- 

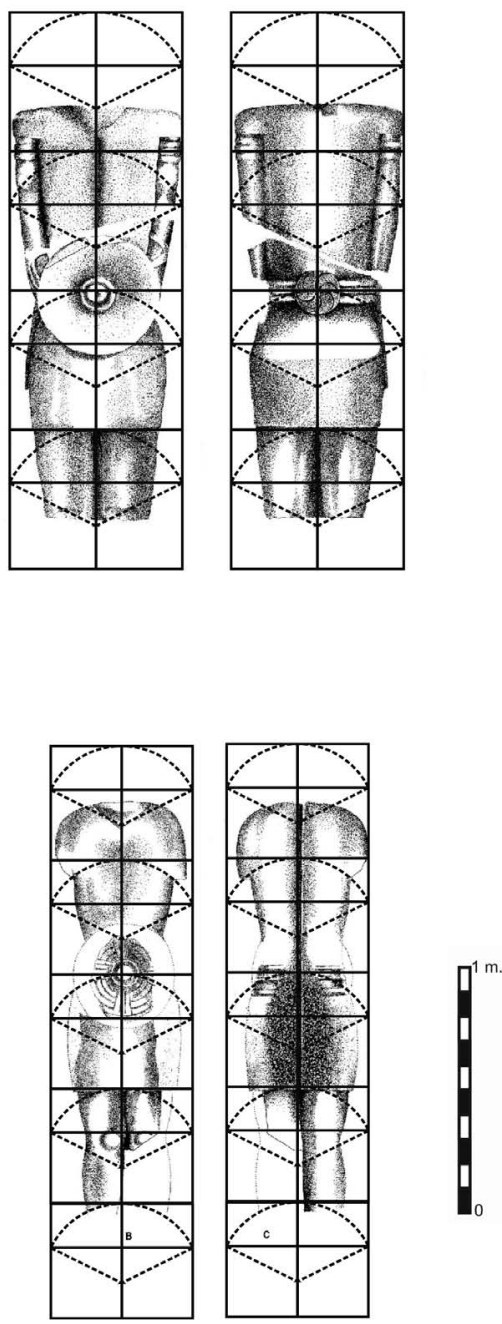

Fig. 6

Arriba: Santo Ovidio de Fafe. Abaixo: Vizela. (A partir de debuxo de Silva, A.C.F., 1986)

tes. Soamente atopamos coincidencias no cinto e no remate do sagum. Respecto ó escudo é un dos dous casos nos que non se observa a aplicación Proporción Harmónica.

\section{Vizela}

Foi atopada no adro da igrexa parroquial de S. Jorge de Vizela, (Figueiras-Porto). Actualmente encóntrase no Museu Arqueológico da Sociedade Martins Sarmento 
en Guimarães (Fig. 6). A falta de brazos e o feito de que teña sido puntualmente reconstruída limita aínda máis as medicións. De tódolos xeitos, obsérvase que as diagonais definen a forma do escote e dúas liñas horizontais coinciden co centro do escudo e liña superior do cinto e co remate do sagum. O escudo semella seguir a Proporción Áurea en canto á relación entre os diámetros do umbo e do escudo.

\section{Sanfins}

Atopado no castro de Sanfíns (Paços de Ferreira-Porto), é o único do que se ten certa certeza sobre a súa posición orixinal, xa que foi localizado o pedestal incrustado nun penedo dende a que se domina unha das entradas ó castro. Actualmente atópase depositado no Museu do Castro de Sanfíns. (Fig. 7). Aínda que tamén se conservan parte das pernas os pés e o pedestal, as proporcións non están claras con respecto á altura, polo que optamos por limitar o traballo á parte superior da estatua. Non se conserva a parte inferior á cintura, aínda que si temos a cabeza, o cal permítenos certa precisión no estudo desta parte da anatomía.

As medicións non nos permiten afirmar ningún extremo, aínda que en todo caso, esta escultura non segue as proporcións xerais das restantes, que semellan coincidir coa Proporción Harmónica, no caso de Sanfíns as proporcións son máis alongadas. Os resultados non nos permiten advertir coincidencias significativas.

\section{Sta. Comba de Bastos}

Foi localizado nas inmediacións do castro de Santa Comba de Refojos no concello de Cabeceiras de Basto (Fig. 7). Forma parte dunha colección particular.

Respecto ás proporcións totais, unha vez máis atopamos os 10 rectángulos áureos. As coincidencias non semellan suficientemente significativas como para asegurar que se teña empregado a Proporción Harmónica. Así e todo, o escudo si segue a Proporción Harmónica do mesmo modo que a maioría das esculturas de guerreiros.

\section{AnÁlise dos Resultados}

Tendo en conta as medicións é posible considerar como moi probable a aplicación da Proporción Harmónica en 6 das 10 esculturas: Lezenho 1 e 2, Campos 1 e 2, Meixedo e São Julião; das 4 restantes é probable que tamén fose aplicada en Sto. Ovidio e incluso en Vizela; respecto a Santa Comba semella moi pouco probable e Sanfins non podemos asegurar ningún extremo. En definitiva, entre un $60 \%$ e un $80 \%$ dos casos poderían ter seguido a aplicación da Proporción Harmónica na execución das esculturas. 

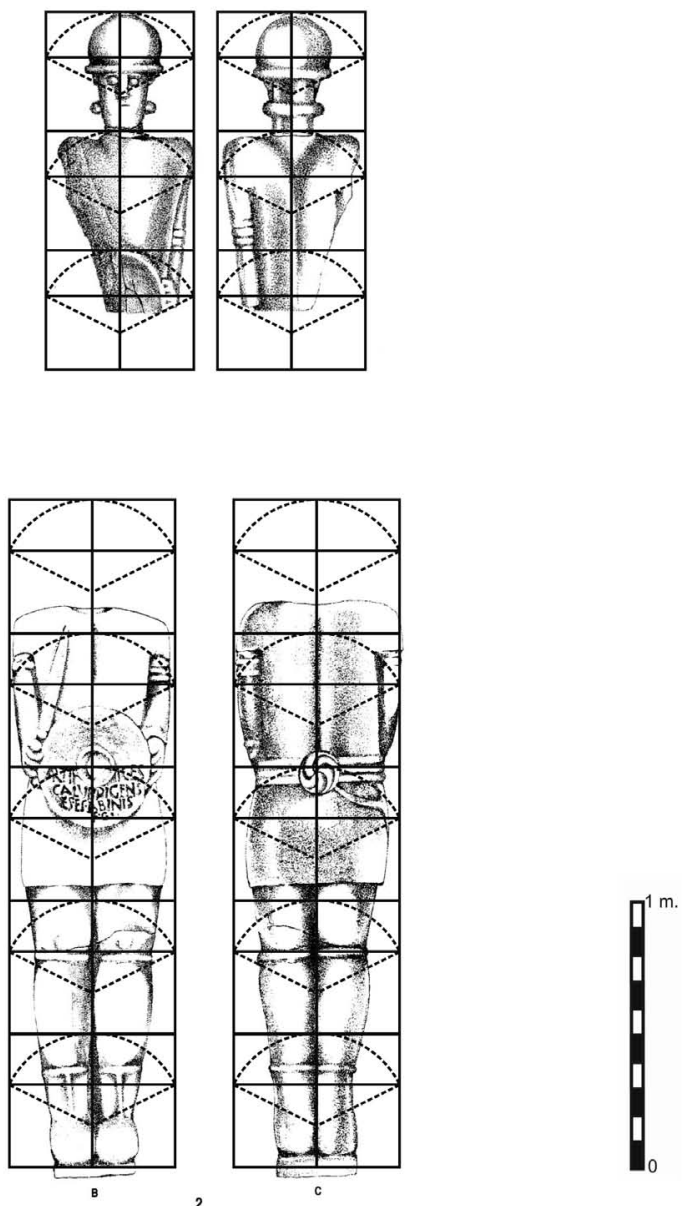

Fig. 7

Arriba: Sanfins. Abaixo: Santa Comba de Basto (A partir de debuxo de Silva, A.C.F., 1986)

Tendo seguido o mesmo procedemento para as medicións de tódalas esculturas, podemos sintetizar os resultados, en canto á aplicación da Proporción Áurea, nos seguintes puntos:

1. Se o ancho da figura se establece en dous rectángulos verticais, a altura é de 5 rectángulos.

2. Puidéronse medir as proporcións de 8 escudos, dos que 6 seguen a Proporción Harmónica, é dicir, a razón entre o diámetro do umbo e o diámetro total do escudo é 1,618 . 
3. As liñas horizontais que delimitan os rectángulos e as que marcan a subdivisión interna dos mesmos, soen coincidir cos mesmos elementos: liña inferior que marca a posición dos brazaletes, centro do escudo, liña superior que marca a posición do cinto e límite inferior do sagum.

4. En menor medida poden aparecer marcados outros elementos como o escote e os xeonllos.

5. A figura formada polos arcos e diagonais dos rectángulos superiores semellan marcar a posición da cabeza.

En definitiva o resultado semella claro polo menos en 6 das esculturas e soamente 2 serían claramente descartables. Debemos ter en conta que ningunha das esculturas está completa, polo que cabería esperar que, de contar con algunhas figuras enteiras, as coincidencias poderían incrementarse e, sen dúbida, sería posible aportar maiores precisións que afectarían á posición dos pés, das grebas, da cabeza, etc.

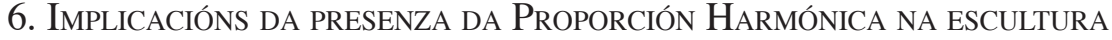 GALAICA}

A mostra analizada non é moi ampla, por elo é pronto para afirmar ata que punto foi aplicada a Proporción Harmónica na escultura galaica, pero o grado de coincidencias en 6 das estatuas permítenos afirmar que nalgúns casos a aplicación desta proporción foi sistemática e polo tanto intencional. Así e todo, tamén é certo que nalgunha escultura non semella haber moitas evidencias con respecto á aplicación desta proporción, como no caso de Santo Ovidio de Fafe e Santa Comba de Basto. Así mesmo, aínda que fora da lista presentada aquí, tampouco semella ter sido aplicada a Proporción Áurea en Capeludos e São João de Ver, estas mostran un deseño formal distinto ás restantes esculturas e, como xa dixemos, unha delas, a de Ver, case con toda seguridade habería que situala na Idade do Bronce ou nos primeiros momentos da Idade do Ferro, xa que o armamento que porta é máis propio distes períodos e o aspecto formal da figura achégao máis ás esculturas da Idade do Bronce que ás da Idade do Ferro. Por outra banda, a de Capeludos, tamén presenta a peculiaridade do seu tamaño, sensiblemente inferior á das restantes esculturas, por outra banda, o armamento tamén é distinto: casco cónico e escudo convexo. O tamaño de Capeludos e o armamento aproxímao ós guerreiros de Sabanle e Melgaço, os cales poderían ter unha cronoloxía máis temperá ${ }^{16}$. En todo caso, o escudo cóncavo das estatuas

\footnotetext{
16 Manuel Santos Estévez e Castor Manuel Pérez Paredes, “Aportacións sobre a estatuaria de guerreiros galaicos a raíz da aparición de dúas novas estátuas en Melgaço y Quintela", Revista de Ciências Historicas, IV (1989), páxs. 51-64.
} 
galaicas clásicas correspóndese coa descrición que Estrabón fai dos escudos do noroeste, que cabería encadrala nun momento serodio, coincidente cos primeiros momentos da conquista romana, xa que dito autor grego bebe de Posidonio, cuxa fonte sería a expedición de Decimo Iunio Bruto no século II a. C. Polo tanto, é moi posible que as esculturas de Capeludos, Sabanle e Melgaço, se sitúen nun momento relativamente temperán da produción escultórica galaica e que non sería ata o século II a. C. cando aparezan as esculturas clásicas de guerreiros e sexa introducida a Proporción Harmónica na súa produción.

Respecto á historiografía sobre a cronoloxía das esculturas de guerreiros, recomendamos a lectura de Höck onde se analizan as distintas propostas ó respecto, por elo non vamos profundar en cuestións historiográficas ${ }^{17}$. Pola nosa banda, inclinámonos por compartir o dito por González Ruibal ${ }^{18}$, quen sostén que as inscricións latinas que posúen as esculturas, non son válidas para datar as estatuas, no caso de Refojos é evidente, a inscrición data do século XVII. Por outra banda, os poucos casos nas que foron atopadas nun contexto arqueolóxico claro, datable en torno ó s. I d. C., as esculturas estaban reutilizadas en construcións, é dicir, que nese momento, este tipo de produción material xa está en desuso. A isto debemos engadir que as inscricións que presentan algunhas esculturas carecen de campo epigráfico propio, aproveitan o espazo que a decoración orixinal da estatua lle deixa. Exemplo disto último é o de Sta. Comba de Basto, onde a inscrición semella interrompida pola presenza do umbo do escudo, en S. Julião as letras finais aparecen incompletas ou deformadas para adaptarse ó escaso espazo que o escudo lle ofrece, en definitiva, as esculturas de guerreiros non semellan ter sido concibidas para albergar inscricións.

Unha das características que vinculan esta estatuaria coa tradición local, é o feito de que moitos dos deseños da escultura galaica xa aparecen nos gravados rupestres de Estilo Atlántico: trisqueis, dobre S, círculos concéntricos e cruciformes ${ }^{19}$. Tamén debe traerse a colación a presenza na Pedra da Póvoa dun cervo gravado co estilo formal dos petróglifos atlánticos ${ }^{20}$. Por outro lado, hai que

\footnotetext{
17 Martin HöcK, "Os "Guerreiros Lusitano-Galaicos” na História da Investigação, a súa Datação e Interpretação", Madrider Mitteilungen, 44 (2003), páxs. 51-66.

18 Na páx. 120 de Alfredo GonZÁlez Ruibal, “Artistic expression and material...”.

19 João Fonte, Manuel Santos Estévez, Lara Bacelar Alves e Raquel López Noia, "La Pedra da Póvoa (Trás-Os-Montes, Portugal). Una Pieza Escultórica de la Edad del Hierro", Trabajos de Prehistoria, vol. 66, núm. 2, (2009), páxs. 161-170.

20 Manuel Santos Estévez, Petroglifos y Paisaje Social en la Prehistoria Reciente del Noroeste de la Península Ibérica, Santiago de Compostela, CSIC-Xunta de Galicia, 2008 (TAPA, 38). Ver tamén Fernando Quintas GonZÁlez e Teresa EsPejo Guardiola, "O Monte das Ferraduras (FentánsCotobade): Novos Achádegos de Arte Rupestre. Descripción e Interpretación”, Cuadernos de Estudios Gallegos, 55, núm. 121 (2008), páxs. 53-72.
} 


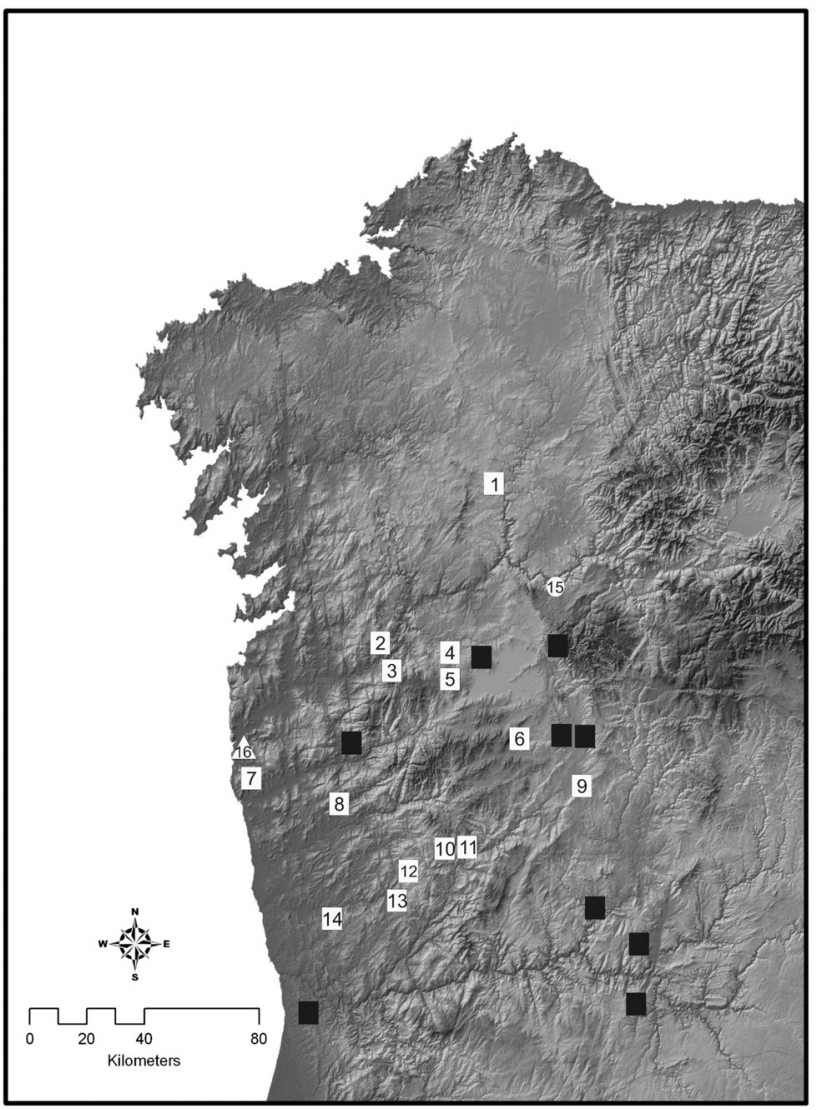

Fig. 8

Os cadrados brancos representan as esculturas de guerreiros: 1, Ralle (Taboada). 2, Sabanle (Crecente). 3, Melgaço. 4, Armeá (Allariz). 5, Rubiás (Bande). 6, Conxuntos de Lezenho e Campos (Boticas). 7, Meixedo (Viana do Castelo). 8, S. Julião (Vila Verde). 9, Capeludos (Vila Pouca de Aguiar). 10, Basto (Cabeceiras de Basto). 11, Refojos (Cabeceiras de Basto). 12, Sto Ovidio de Fafe (Fafe). 13. Vizela (Guimarães). 14, Sanfins (Paços de Ferreira). O triángulo é a puerta da Cidade de Áncora (Caminha) e os cadrados negros son as estelas/menhir da Idade do Bronce.

lembra-la existencia de certa tradición local escultórica no noroeste da Península Ibérica dende a Idade do Bronce, como xa sinala Silva que se iniciaría coas esculturas antropomorfas e estatuas-menhir ${ }^{21}$. En relación a este punto hai que sinala-la coincidencia entre a distribución de ditas estatuas-menhir e as esculturas de guerreiros, aínda que non haxa que esquecer que ambos tipos de escultura

\footnotetext{
${ }^{21}$ Na páx. 45 de Armando Coelho Ferreira da SiLva, "Expressões Guerreiras da Sociedade Castreja", Madrider Mitteilungen, 44, (2003), páxs. 41-50.
} 
difiran significativamente na súa cronoloxía. (Fig. 8). De tódolos xeitos, non hai que descartar que a orixe da tradición estatuaria houbese que remontala á Idade do Bronce. Respecto a esta posibilidade, São João de Ver podería representar unha fase intermedia entre as esculturas típicas do Bronce e as da Idade do Ferro, cuxa fase inicial estaría representada polas figuras de Capeludos, Sabanle e Melgaço, anteriores ó desenvolvemento das esculturas clásicas. Por esta razón vinculamos as esculturas, obxecto do presente estudo, ós últimos séculos inmediatamente anteriores ó cambio de era e, posiblemente, serían os séculos II e I a. C. cando sería introducida a Proporción Harmónica na produción da maioría das esculturas de guerreiros galaicos.

Pero a presenza de esculturas como Santa Comba de Basto ou Santo Ovidio de Fafe, tamén estarían evidenciando que a Proporción Harmónica non foi adoptada en tódolos casos, non cabería atribuír grandes diferenzas cronolóxicas entre as pezas con e sen Proporción Harmónica, xa que Sta. Comba é formalmente encadrable dentro do grupo de esculturas clásicas, aínda que quizais podería haber pequenas diferenzas cronolóxicas, para Schattner Sta. Comba sería, posiblemente, unha das máis antigas ${ }^{22}$, quizais sexa esta a razón da ausencia da Proporción Áurea. Por outra banda, non poderíamos argumentar razóns territoriais, xa que tanto Sta. Comba como Fafe, sitúanse en pleno territorio de distribución das esculturas de guerreiros, encadrado entre o Douro no límite sur e o Támega no oeste.

\section{A Proporción Harmónica como símbolo social e político}

A aplicación da Proporción Áurea a calquera produción material require un alto grado de formación por parte do artesán, arquitecto ou artista. En primeiro lugar, debemos ter en conta que a elección dunha determinada proporción, leva consigo implicacións de carácter filosófico e/ou relixioso. No Renacemento, por exemplo, recupérase o canon greco-romano a través da republicación de $D e A r$ chitectura de Vitruvio en 1486, trátase dunha elección plena de reflexión, onde se reivindica o mundo clásico e a observación da natureza (ou da obra divina), como fonte de coñecemento. Ó contrario, o canon bizantino, mantido pola Igrexa Ortodoxa a través de séculos, busca lexitimidade na tradición medieval ${ }^{23}$.

Pero, ó mesmo tempo, o feito de usar de forma sistemática unha determinada proporción ou un canon para as proporcións do corpo humano, denota unha intención integradora, máis propia de estados centralizados, como por exemplo

\footnotetext{
22 Thomas. G. SchatTNER, "Novas aproximações às estátuas de guerreiros lusitano-galaicos", $O$ Arqueólogo Portugués, IV, 22 (2004), páxs. 9-66.

23 Erwin Panofsky, La perspectiva como forma simbólica, Barcelona, Tusquets, 1973 e Renacimiento y renacimientos en el arte occidental, Madrid, Alianza, 1975.
} 
o antigo Exipto. O uso sistemático dun determinado canon non implica a existencia dun sistema político centralizado, pero é unha condición para que este funcione. Un sistema político deste tipo e un sistema unificado de proporcións para a produción material, son dous aspectos compatibles estruturalmente.

$\mathrm{O}$ feito de que na Segunda Idade do Ferro do Noroeste Ibérico se decida adoptar unha determinada proporción para boa parte das esculturas onde se retratan ás elites, puidera ser indicativo de que estea xurdindo un novo sistema de saberpoder que implica unha nova relación entre espazo, pensamento e sociedade e, polo tanto, unha nova forma de pensar e representar o mundo ${ }^{24}$. Semella quedar atrás unha concepción do espazo como algo secuencial que adquire sentido ó desprazarse por el, onde os monumentos se situaban ó longo de liñas de tránsito ${ }^{25}$. Neste novo período, irrompe unha nova concepción da paisaxe, o chan vírase en algo mensurable, como corresponde a unha sociedade sedentaria, estratificada e plenamente campesiña ${ }^{26}$. A superficie da terra parcélase, ó igual que o fan as esculturas. A aplicación dunha determinada proporción nun produto material só se comprende dentro dunha cultura que concibe o espazo como algo divisible sistematicamente. No caso do Noroeste Ibérico prerromano, non podemos falar dun sistema estatal centralizado, pero si de que se están a construír as condicións para que este se produza. Polo menos no sur de Gallaecia, estas condicións poderían ter a súa tradución material nalgunhas evidencias materiais arqueolóxicas, como a escultura monumental e a construción de oppida. A grande inversión de traballo empregado nas construcións monumentais nos lugares centrais, como é o caso das esculturas e murallas dos oppida no caso que nos ocupa, podería ser interpretado como un síntoma da existencia dun sistema político centralizado ${ }^{27}$.

Como dicíamos, a aplicación da Proporción Harmónica á escultura require certo grado de formación profesional, que xeralmente debe corresponderse con certa especialización do artesán. Tanto se a adopción da Proporción Harmónica se produciu antes ou despois da conquista romana aínda que, polo xa argumentado no apartado anterior, inclínome a pensar que debeu ser antes, considerábase posible que os escultores encargados de executar as estatuas puideron ter sido

\footnotetext{
${ }^{24}$ Michael Foucault, La arqueología del saber, México, Siglo XXI, 1979. Felipe Criado BoAdo, "Límites y Posibilidades de la Arqueología del Paisaje", SPAL, 2 (1993), páxs. 9-55.

25 Felipe Criado Boado, "Límites y Posibilidades...”, Felipe Criado Boado e Jacobo Vaquero Lastres, "Monumentos, nudos en el pañuelo. Megalitos: nudos en el espacio. Análisis del emplazamiento de los monumentos tumulares gallegos", Espacio, Tiempo y Forma, serie I, t. 6 (1993), páxs. 205-48.

${ }^{26}$ Manuel Santos Estévez, "Some notes about social space and its influence in the design of labyrinth figure", Man in India, vol. 88, núm. 2/3 (2008), páxs. 357-366.

27 Timothy Earle, "Chiefdoms in archaeological and etnohistorical perspective", Annual Review of Anthropology, 16 (1987), páx. 290.
} 
formados fora do ámbito cultural galaico. Segundo Helms o coñecemento distingue a unhas persoas doutras e as eleva na consideración social, o coñecemento esotérico é o coñecemento do inusual e do exótico ${ }^{28}$. Se os escultores galaicos, a xulgar polo estilo dos seus produtos, eran artesáns locais, é posible que o coñecemento que aplicaban á produción de esculturas onde se representa á elite social, fora adquirido máis aló das fronteiras culturais do ámbito galaico, e non debemos descartar a posibilidade de que tamén estes artesáns, baixo o patrocinio dun xefe ou rei, foran enviados fora dos seus territorios, tal e como ten ocorrido noutras sociedades ${ }^{29}$. Este territorio culturalmente alleo, non sabemos se tamén político, puido ter sido o romano ou o celta. Certa influencia romana semella reflectirse nos resultados das análises estilísticas de Schattner, quen presenta a posibilidade do uso do contraposto, o cal sería adoptado nas esculturas máis $\operatorname{tardías}^{30}$. Así como a presenza romana en Hispania puido ser un dos factores que propiciaron o incremento da xerarquización na sociedade galaica e o xurdimento de estruturas políticas máis complexas ${ }^{31}$, tamén puido funcionar como suministrador de recursos simbólicos para o sostemento desta elite retratada nas esculturas, tal e como puido ocorrer entre os iberos. A influencia do mundo romano produciríase pouco antes da conquista, quizais seguindo un proceso similar ó producido séculos antes en Europa central ou na cultura ibera a través dos vínculos comerciais coas sociedades complexas do Mediterráneo ${ }^{32}$. En definitiva, aínda que a influencia romana desempeñaría certo papel no desenvolvemento das estatuas galaicas de guerreiros, estas serían froito do substrato cultural galaico, un produto indíxena que contaba cunha importante tradición local adaptada a un novo contexto histórico. Polo tanto, estaríamos lonxe de considerar a estas esculturas como un arte provincial tal e como é nomeado por Calo ${ }^{33}$. Así e todo, non debemos descartar a orixe celta da implementación da Proporción Harmó-

\footnotetext{
${ }^{28}$ Nas páxs. 11 e 12 de Mary. W. HeLms, Ulysses'Sail. An ethnographic odyssey of power, knowledge, and geographical distance, New Jersey, Princeton University Press, 1988.

${ }^{29}$ Na páx. 34 de Mary. W. Helms, Craft and the Kindly Ideal. Art, trade, and power, Austin University of Texas Press, 1993.

30 Thomas G. SchattNer, "Novas aproximações às estátuas de guerreiros lusitano-galaicos", $O$ Arqueólogo Portugués, IV, 22 (2004), páxs. 9-66.

${ }^{31}$ Jorge de Alarcão, "As estátuas de guerreiros galaicos como representaçôes de príncipes no contexto da organizaçâo político - administrativa do noroeste pré-flaviano", Madrider Mitteilungen, 44 (2003), páxs. 116-126. Alfredo González Ruibal, Galaicos: poder y comunidad en el Noroeste de la Península Ibérica (1200 a.C.-50 d.C.), A Coruña, Museo Arqueolóxico e Histórico da Coruña, 2006-2007, vol. 1, páx. 450.

32 Teresa ChAPA BRUNET, "Algunas reflexiones acerca del origen de la escultura ibérica", Revista de Estudios Ibéricos, núm. 1 (1994), páxs. 43-60.

${ }^{33}$ Francisco CAlo Lourido, “Arte, decoración, simbolismo...”, páxs. 159-85.
} 
nica, xa que boa parte da decoración galaica, garda estreitas semellanzas coa presente na produción material celta de Europa Occidental.

En definitiva, consideramos que a aplicación da Proporción Harmónica á escultura galaica é o reflexo da existencia de artesáns especialistas cuxo traballo estaría orientado a, e sufragado por, as elites, as cales serían retratadas portando o produto doutros artesáns especializados na produción de bens de prestixio: torques e cintos dos ourives, roupa dos tecedores, armas dos ferreiros. Por primeira vez na Idade do Ferro do Noroeste, o enxalzamento dos individuos pertencentes á elite non se fai soamente a través de obxectos mobles, senón tamén a través de monumentos: releves en arquitecturas e esculturas ${ }^{34}$. De feito, a grande maioría da escultura galaica ten como finalidade formar parte de arquitecturas: pedras formosas, releves para inxerir en paredes, xambas, linteis, etc. A excepción témola na estatuaria antropomorfa, aínda que esta semella ter sido executada por artesáns acostumados a traballar con releves máis que en escultura propiamente dita. É dicir, as figuras de guerreiros están formadas por catro planos que, configurados como un paralelepípedo, dan lugar a unha estrutura tridimensional, un síntoma máis do seu vínculo coa tradición local. Este incremento na inversión en arte inmoble, coincide cun incremento na inversión de traballo na construción de asentamentos, os oppida, que puideron funcionar como centros políticos de territorios de certa amplitude, quizais relacionados con posibles santuarios fronteirizos como propoñen García e Santos e polo tanto seguir unha estruturación ideolóxica, política e social nova ${ }^{35}$. A presenza da Proporción Harmónica nun tipo de escultura estandarizada, como son as dos guerreiros galaicos, obedece a unha vontade de compartir, por parte dunha elite, propia de sociedades organizadas en xefaturas, un mesmo código simbólico que os equipara como grupo social a outros grupos dominantes veciños e que os distingue do común das respectivas poboacións locais, tal e como semella suceder noutras sociedades organizadas en xefaturas complexas ${ }^{36}$; parte deste código puido ter sido importado dunha cultura allea ou ser produto do propio enxeño. En todo caso, o uso dun determinado código estético común debeu servir como útil simbólico ante unha nova cultura, a romana, coa que tocaría negociar, medirse e lexitimarse nos últimos séculos anteriores ó cambio de era.

\footnotetext{
${ }^{34}$ Manuel Santos Estévez, "Atlantic Rock Art: transformation and tradition in Late Prehistory", en María Cruz Berrocal, Leonardo García Sanjuán, Antonio Gilman (ed.), The Prehistory of Iberia. Debating Early Social Stratification and the State, London, Routledge, 2012.

35 Marco Virgilio García Quintela e Manuel Santos Estévez, Santuarios de la Galicia Céltica, Madrid, Ed. Abada, 2008.

${ }^{36}$ Timothy EARLE, "Style and iconography as legitimation in complex chiefdoms", en M. W. Conkey and G. A. Hastorf (eds.), The uses of style in archaeology, Cambridge, Cambridge University Press, 1990, páxs. 73-81. Alfredo González Ruibal, "La Vida Social de los Objetos Castreños", en F. J. González (Coord.), Los Pueblos de la Galicia Céltica, Madrid, Ed. Akal, 2007, páxs. 259-322.
} 


\section{BIBLIOGRAFÍA}

Alarcão, Jorge de, "As estátuas de guerreiros galaicos como representaçôes de príncipes no contexto da organizaçâo político-administrativa do noroeste pré-flaviano", Madrider Mitteilungen, 44 (2003), páxs. 116-126.

Calo Lourido, Francisco, "Arte, decoración, simbolismo e outros elementos da cultura material castrexa, ensaio de síntese", en G. Pereira Menaut (ed.). Estudos de cultura castrexa e de historia antiga de Galicia, Compostela, Universidad, Servicio de Publicaciones, 1983, páxs. 159-185.

Calo Lourido, Francisco, A Plástica da Cultura Castrexa Galego-Portuguesa, A Coruña, Fundación Pedro Barrié de la Maza, Conde de Fenosa, 1994, 2 vols. (Catalogación arqueológica y artística de Galicia).

Calo Lourido, Francisco, "Catálogo”, Madrider Mitteilungen, 44 (2003), páxs. 6-32.

Chapa Brunet, Teresa, "Algunas reflexiones acerca del origen de la escultura ibérica", Revista de Estudios Ibéricos, 1 (1994), páxs. 43-60.

Criado Boado, Felipe, "Límites y Posibilidades de la Arqueología del Paisaje", SPAL 2 (1993), páxs. 9-55.

Criado Boado, Felipe e Vaquero Lastres, Jacobo, "Monumentos, nudos en el pañuelo. Megalitos: nudos en el espacio. Análisis del emplazamiento de los monumentos tumulares gallegos", Espacio, Tiempo y Forma, serie I, T. 6 (1993), páxs. 205-48.

Earle, Timothy, "Chiefdoms in archaeological and etnohistorical perspective", Annual Review of Anthropology, 16 (1987), páxs. 279-308.

Earle, Timothy, "Style and iconography as legitimation in complex chiefdoms", en M. W. Conkey and G. A. Hastorf (eds.), The uses of style in archaeology, Cambridge, Cambridge University Press, 1990, páxs. 73-81.

Fonte, João, Santos Estévez, Manuel, Bacelar Alves, Lara e López Noia, Raquel, "La Pedra da Póvoa (Trás-Os-Montes, Portugal). Una Pieza Escultórica de la Edad del Hierro", Trabajos de Prehistoria, vol. 66, núm. 2 (2009), páxs. 161-170.

Foucault, Michael, La arqueología del saber, México, Siglo XXI, 1979.

Fuente, Beatriz de la, Los hombres de piedra. Escultura olmeca, México, Instituto de Investigaciones Estéticas, UNAM,1977.

García Quintela, Marco Virgilio e Santos Estévez, Manuel, Santuarios de la Galicia Céltica, Madrid, Editorial Abada, 2008.

Ghyka, Matila, Estética de las Proporciones en la Naturaleza y en las Artes. Buenos Aires, Ed. Poseidón, 1953.

Ghyka, Matila, El número de oro, Buenos Aires, Ed. Poseidón, 1968.

González Ruibal, Alfredo, "Artistic expression and material culture in Celtic Gallaecia", EKeltoi, 6 (2004), páxs. 113-166.

González Ruibal, Alfredo, Galaicos: poder y comunidad en el Noroeste de la Península Ibérica (1200 a.C.-50 d.C.), A Coruña, Museo Arqueolóxico e Histórico da Coruña, 20062007, 2 vols. (Colección Brigantium, 18-19).

González Ruibal, Alfredo, "La Vida Social de los Objetos Castreños", en F. J. González (Coord.), Los Pueblos de la Galicia Céltica, Madrid, Ed. Akal, 2007, páxs. 259-322. 
Goody, Jack, La Domesticación del Pensamiento Salvaje, Madrid, Ed. Akal, 1985.

Helms, Mary, W. Ulysses' Sail. An ethnographic odyssey of power, knowledge, and geographical distance, New Jersey, Princeton University Press, 1988.

Helms, Mary, W. Craft and the Kindly Ideal. Art, trade, and power, Austin, University of Texas Press, 1993.

Höck, Martin, "Os Guerreiros Lusitano-Galaicos na História da Investigação, a súa Datação e Interpretação", Madrider Mitteilungen, 44 (2003), páxs. 51-66.

Jorge, Vitor Oliveira e Jorge, Susana Oliveira, "Statues-Menhirs et Stèles du Nord du Portugal”, Revista da Facultade de Letras: História, serie II, vol 7 (1990), páxs. 299-324.

Markowsky, George, "Misconceptions about the golden ratio" The College Mathematics Journal, vol. 23, núm. 1 (Jan.1992), páxs. 2-19.

Panofsky, Erwin, La perspectiva como forma simbólica, Barcelona, Tusquets, 1973.

Panofsky, Erwin, Renacimiento y renacimientos en el arte occidental, Madrid, Ed. Alianza, 1975.

Quintas González, Fernando e Espejo Guardiola, Teresa, "O Monte das Ferraduras (FentánsCotobade): Novos Achádegos de Arte Rupestre. Descripción e Interpretación”, Cuadernos de Estudios Gallegos, 55, núm. 121 (2008), páxs. 53-72.

Sampoelesi, Roberto, La Divina Proporción y la Retina, Buenos Aires, Olmo Ediciones, 2006.

Santos Estévez, Manuel, Petroglifos y Paisaje Social en la Prehistoria Reciente del Noroeste de la Península Ibérica, Santiago de Compostela, Laboratorio de Arqueoloxía do Instituto de Estudos Galegos Padre Sarmiento; Xunta de Galicia, 2008 (TAPA, 38).

Santos Estévez, Manuel, "Some notes about social space and its influence in the design of labyrinth figure", Man in India, vol. 88, núm. 2/3 (2008), páxs. 357-366.

Santos Estévez, Manuel, "Atlantic Rock Art: transformation and tradition in Late Prehistory", en Cruz Berrocal, García Sanjuán \& Gilman Guillén (eds), The Prehistory of Iberia. Debating Early Social Stratification and the State, Londres, Routhledge, 2012.

Santos Estévez, Manuel e Pérez Paredes, Castor Manuel, "Aportacións sobre a estatuaria de guerreiros galaicos a raíz da aparición de dúas novas estátuas en Melgaço e Quintela", Revista de Ciências Historicas, IV (1989), páxs. 51-64.

Schattner, Thomas G, "Novas aproximações às estátuas de guerreiros lusitano-galaicos", $O$ Arqueólogo Portugués, IV, 22 (2004), páxs. 9-66.

Silva, Armando Coelho Ferreira da, A Cultura Castreja do Noroeste de Portugal, tese doutoral inédita, Paços de Ferreira, Museu Arqueólogico da Citânia de Sanfins, 1986.

Silva, Armando Coelho Ferreira da, "Expressões Guerreiras da Sociedade Castreja", Madrider Mitteilungen, 44 (2003), páxs. 41-50.

Tranoy, Alain, La Galice romaine. Recherches sur le nord-ouest de la péninsule Ibérique dans l'Antiquité, Paris, Editado por Diffusión De Boccard, 1981.

Velandia Jagua, César Augusto, Iconografía funeraria en la cultura arqueológica de San Agustín-Colombia, Ibagué, Universidad del Tolima, 2011. 